\title{
The Impact of Health Literacy on Surgical Outcomes Following Radical Cystectomy
}

\section{Kristen R. Scarpato, MD MPH,}

Vanderbilt University Medical Center, Department of Urologic Surgery, $116121^{\text {st }}$ Ave South, A-1302 MCN, Nashville, TN 37232, kristen.r.scarpato@vanderbilt.edu

\section{Stephen F. Kappa, MD,}

Vanderbilt University Medical Center, Department of Urologic Surgery, $116121^{\text {st }}$ Ave South, A-1302 MCN, Nashville, TN 37232, Stephen.kappa@vanderbilt.edu

\section{Kathryn M. Goggins, MPH,}

Vanderbilt University Medical Center, Center for Health Services Research, $121521^{\text {st }}$ Ave. South, MCE Suite 6000, Nashville, TN 37232, Kathryn.m.goggins@vanderbilt.edu

\section{Sam S. Chang, MD MBA,}

Vanderbilt University Medical Center, Department of Urologic Surgery, $116121^{\text {st }}$ Ave South, A-1302 MCN, Nashville, TN 37232, Sam.chang@vanderbilt.edu

Joseph A. Smith Jr., MD,

Vanderbilt University Medical Center, Department of Urologic Surgery, $116121^{\text {st }}$ Ave South, A-1302 MCN, Nashville, TN 37232, Joseph.smith@vanderbilt.edu

Peter E. Clark, MD,

Vanderbilt University Medical Center, Department of Urologic Surgery, $116121^{\text {st }}$ Ave South, A-1302 MCN, Nashville, TN 37232, Peter.clark@vanderbilt.edu

\section{David F. Penson, MD MPH,}

Vanderbilt University Medical Center, Department of Urologic Surgery, $116121^{\text {st }}$ Ave South, A-1302 MCN, Nashville, TN 37232, David.penson@vanderbilt.edu

\section{Matthew J. Resnick, MD MPH,}

Vanderbilt University Medical Center, Department of Urologic Surgery, $116121^{\text {st }}$ Ave South, A-1302 MCN, Nashville, TN 37232, Matthew.resnick@vanderbilt.edu

\section{Daniel A. Barocas, MD MPH,}

Vanderbilt University Medical Center, Department of Urologic Surgery, $116121^{\text {st }}$ Ave South, A-1302 MCN, Nashville, TN 37232, Dan.barocas@vanderbilt.edu

\section{Kamran Idrees, MD,}

Vanderbilt University Medical Center, Department of Surgery, 2220 Pierce Ave, 597 PRB, Nashville, TN 37232-6860, Kamran.idrees@vanderbilt.edu

Sunil Kripalani, MD MSc, and 
Vanderbilt University Medical Center, Department of Medicine, $6^{\text {th }}$ Floor, MCE, Nashville, TN 37232-8300, sunil.kripalani@vanderbilt.edu

Kelvin A. Moses, MD PhD

Vanderbilt University Medical Center, Department of Urologic Surgery, $116121^{\text {st }}$ Ave South, A-1302 MCN, Nashville, TN 37232, Kelvin.a.moses@vanderbilt.edu

\section{Abstract}

Health literacy is the ability to obtain, comprehend and act on medical information and is an independent predictor of health outcomes in patients with chronic health conditions. However, there is little reported regarding the potential association of health literacy and surgical outcomes. We hypothesized that patient complications after radical cystectomy (RC) are associated with health literacy. In a sample of 368 patients, we found that higher health literacy scores (as determined by the Brief Health Literacy Screen) are associated with decreased odds of developing minor complications (OR=0.90, 95\% CI: 0.83,0.97). Health literacy should be considered when caring for patients undergoing radical cystectomy and serve as a potential indicator of the need for additional resources to improve post-operative outcomes.

\section{Keywords}

health literacy; bladder cancer; complications; radical cystectomy

\section{Background}

Bladder cancer will account for an estimated 74,000 new cancer diagnoses and 16,000 deaths in the United States in 2015 (Siegel, Miller, \& Jemal, 2015). At the time of diagnosis, nearly one quarter of patients have muscle-invasive bladder cancer (MIBC), which is aggressive and potentially fatal (Amin et al., 2013). The standard of care in the treatment of MIBC is radical cystectomy (RC), which entails removal of the urinary bladder and pelvic lymph nodes, and creation of a urinary diversion. The procedure is complex and requires significant post-operative care during both the immediate post-surgical hospitalization and after discharge from the hospital. An incontinent diversion, usually an ileal conduit, remains the most common form of urinary diversion and necessitates facility and understanding managing a urinary stoma and its required supplies, such as a skin barrier device and collection bag. Similarly, patients who have a continent urinary diversion, such as an orthotopic neobladder or Indiana pouch, must learn to intermittently catheterize for elimination of urine, which requires the ability to understand basic anatomy, adhere to a set of directives and follow a schedule. Regardless of intervention type, all patients who undergo RC require significant self-care following hospitalization, including management of supplies and the ability to follow detailed verbal and written self-management instructions.

Health literacy, as defined by the Institute of Medicine, is the ability to obtain, comprehend and act on medical information (Nielsen-Bohlman \& Institute of Medicine (U.S.).

Committee on Health Literacy., 2004), and is an independent predictor of health outcomes in patients with chronic health conditions (Cavanaugh et al., 2010; Peterson et al., 2011). Low 
health literacy has also been associated with worse global health status (Safeer \& Keenan, 2005). Additionally, health care providers may over-estimate a patient's health literacy, which arguably impacts patient education and has been identified as a potential source of health care disparities (Kelly \& Haidet, 2007; Safeer \& Keenan, 2005).

While the impact of health literacy on chronic medical conditions is better studied, its role in surgical morbidity is not yet characterized. Due to the need for significant post-surgical selfcare, $\mathrm{RC}$ patients compose an ideal population of surgical patients to investigate the relationship between health literacy and surgical outcomes.

\section{Methods}

Beginning November 2010, the Brief Health Literacy Screen (BHLS) was added to the inpatient nursing documentation at our large, tertiary hospital [Figure 1]. This validated screening tool consists of the following three questions, which are verbally administered by the nursing staff and added to the electronic health record (EHR) (Chew, Bradley, \& Boyko, 2004):

1. How confident are you filling out medical forms by yourself?

2. How often do you have someone help you read hospital materials?

3. How often do you have problems learning about your medical condition because of difficulty understanding written information?

Patient responses are evaluated using a 5-point Likert-type scale, with the total score ranging from 3 (lowest score) to 15 (highest score). These questions have been previously shown to correlate with other measures of health literacy, including the Short Test of Functional Health Literacy in Adults (S-TOFHLA) and Rapid Estimate of Adult Literacy in Medicine (REALM) (Chew et al., 2008). There is not a defined cut point delineating "adequate/high literacy" from "inadequate/low literacy", so for the purposes of this study and ease of interpretation we set the threshold for determining health literacy at the median to facilitate comparison between "low" and "high" health literacy groups.

Demographic and clinical characteristics for all RC patients since November 2010 were abstracted by key study personnel from the RC database stored in REDCap (Table 1) (Harris et al., 2009). Data are continuously collected and entered into the database by two dedicated research nurses and then evaluated for completeness and accuracy by a database administrator. All data are prospectively maintained by research staff and can be accessed by key study personnel with appropriate institutional review board (IRB) training. Missing demographic and clinical data was collected from a comprehensive medical record review. Two urologists (KS, SK) assured final data quality prior to data analysis. Health literacy data and educational status were abstracted from the EHRs by the health services research core (HSR) staff according to medical record numbers provided from the REDCap RC database. Patient characteristics examined in our analysis included age, sex, race, educational attainment, comorbidity, marital status, (T)umor classification based on the American Joint Committee on Cancer $7^{\text {th }}$ edition, use of neoadjuvant chemotherapy, and operative details, such as open versus robotic procedure and urinary diversion type. The Elixhauser 
comorbidity index, which is a comorbidity classification system that summarizes disease burden that has been found to be more discriminatory than Charlson score, was also collected because comorbidity score has been shown to impact hospital length of stay, posthospitalization outcomes and mortality (van Walraven, Austin, Jennings, Quan, \& Forster, 2009).

Postoperative complications were collected and analyzed as defined in a recent study on this patient cohort (Stimson et al., 2010) and were then further coded according to the ClavienDindo classification into "major" and "minor" complications. We also included "overall" complication rate. Major complications (Clavien grade III, IV, V) included return to the operating room, myocardial infarction, cerebrovascular accident, respiratory failure, pulmonary embolus, bowel leak, urine leak, sepsis, dehiscence, bowel obstruction and death. Minor complications (Clavien grade I, II) included ileus, urinary tract infection, need for total parenteral nutrition, wound infection, deep venous thrombosis, pneumonia, abscess and lymphocele. Postoperative ileus was defined as: the inability to tolerate a diet by postoperative day 5 , failure of return of bowel function by postoperative day 5 , need for nasogastric tube during hospitalization or persistent nausea/vomiting (Lowrance et al., 2008).

We performed bivariate analyses comparing patients with low health literacy (BHLS score 3 to $13, \mathrm{n}=188$ ) to patients with high health literacy (BHLS score 14 to $15, \mathrm{n}=180$ ) to identify associations between baseline characteristics and health literacy. We then examined the associations between health literacy and postoperative complications by performing a logistic regression analysis adjusted for all clinical and demographic characteristics assessed in the bivariate analyses. And finally, we performed Cox regression to test the association between covariates and time to first emergency department (ED) visit or readmission and logistic regression to test the association between covariates and presence of an ED visits or readmission within 90 days of discharge. All tests of significance were 2-tailed with $\mathrm{P}<$ 0.05 deemed significant. SPSS 22.0 (IBM Corp, Armonk, NY) was used for statistical analysis. The IRB approved all methods.

\section{Results}

A total of 575 patients underwent radical cystectomy between November 2010 and July 2014 and 368 had available health literacy data for analysis (Table 1). The mean age was 67.2 years, with the majority of the study population being white (95.9\%) and male (83.4\%), which reflects the epidemiology of the disease. Median health literacy score for this cohort was 13 (IQR 10-15, range 3-15). The mean educational attainment was 13.3 years and was statistically different between those with high literacy and low literacy $(\mathrm{p}<0.001)$. A greater percentage of high literacy patients were married (84.3\%) compared to those with low literacy $(69.4 \%)(\mathrm{p}=0.001)$. The majority of patients were covered by Medicare and about one third had private insurance. There was no difference between the two health literacy groups with regard to insurance status.

Patients with low literacy tended to have higher pathological T-classification at the time of $\mathrm{RC}(\mathrm{p}=0.022)$. Mean preoperative albumin was statistically lower in patients with BHLS $\leq 3$ 
$(\mathrm{p}=0.001)$. There was no difference in smoking status, BMI, ASA class, Elixhauser score, or abdominal surgical history between the high and low health literacy groups. Similarly, the groups were evenly matched in according to receipt of neoadjuvant chemotherapy, type of urinary diversion and robotic vs. open procedures.

Table 2 summarizes the unadjusted perioperative and postoperative outcomes according to low or high literacy status. The overall complication rate was $42.7 \%$, with $8.4 \%$ categorized as major and $34.2 \%$ minor. Low literacy was significantly associated with having a minor complication $(\mathrm{p}=0.034)$. All other surgical outcomes were not significantly associated with health literacy status.

In multivariable logistic regression analysis (Figure 2), lower health literacy score was significantly associated with developing a minor complication (OR=0.90, 95\% CI: $0.83-$ 0.97). All other covariates were not significantly associated with having a minor complication. Although lower health literacy was associated with having any complication peri-operatively ( $\mathrm{OR}=0.91,95 \% \mathrm{CI}$ : $0.84-0.99$, data not shown), this was largely driven by the association with the development of minor complications. Older age, higher Elixhauser score and having an open procedure were also associated with having any complication after surgery.

Overall, $22.0 \%$ of patients were readmitted within 90 days and $18.2 \%$ of patients had an ED visit within 90 days of discharge (Table 2). Using Cox regression, we found that health literacy was not significantly associated with time to first ED visit or readmission. Elixhauser score was associated with time to both first ED visit and readmission. We found similar results using logistic regression with 90-day ED visit or readmission as the outcome.

\section{Discussion}

In this study, health literacy was significantly associated with having a minor complication following RC after controlling for a comprehensive list of clinical, demographic and social characteristics. Health literacy was not associated with time to first ED visit or readmission or having an unplanned healthcare utilization event.

While there is selected literature to support the importance of assessing health literacy in patients with chronic medical conditions (Cavanaugh et al., 2010; Safeer \& Keenan, 2005; Willens et al., 2013), there are very few data evaluating the impact of health literacy on surgical outcomes. We chose to look at the RC population due to the complexity of the procedure and the requisite intense aftercare, including ability to comprehend detailed verbal and written instructions. $\mathrm{RC}$ is a morbid procedure, with approximately $30 \%$ to $60 \%$ of patients having a post-operative complication, ranging from minor to severe (Lowrance et al., 2008; Shabsigh et al., 2009; Stein et al., 2001). Our population was within this range with $42 \%$ of patients experiencing a complication which suggests that the results of this study are relevant to a high proportion of patients.

Refinements in surgical technique and the development of post-operative pathways, largely designed to avoid bowel complications, have resulted in some success in decreasing morbidity (Daneshmand et al., 2014; Lee et al., 2014; Zaid, Kaffenberger, \& Chang, 2013). 
There remains room for improvement, however, as the scientific advancements in this field have not completely alleviated the amount of self-care that patients must partake in postsurgery. Identifying patients with low health literacy prior to RC can lead to targeted interventions that could include providing additional resources or perioperative health education/training with the goal of ultimately reducing perioperative morbidity.

Additionally, having the BHLS administration built into the normal workflow is an easy way to alert providers, who often overestimate a patient's health literacy status (Kelly \& Haidet, 2007; Safeer \& Keenan, 2005), to patients who might benefit from additional intervention. Ideally, each patient would receive the same, effective, in-depth communication perioperatively but, based on the results of this study, targeted interventions among patients with lower health literacy may be beneficial.

Our results also show that the odds of having any complication are increased for older patients, those with greater Elixhauser score, and those undergoing robotic procedures. Bladder cancer primarily affects older patients and there is concern about performing radical extirpative surgery in the elderly who often have increased comorbidity, greater frailty, and decreased performance status. Studies by Schiffmann and colleagues (Schiffmann et al., 2014) as well as Morgan et al. (Morgan et al. 2011) found higher 90-day mortality with increasing age while Donat and colleagues (Donat et al., 2010) found that RC in octogenarians provided a non-significantly higher rate of major and minor complications, which is consistent with our results. Similarly, we found that those with greater comorbidity, according to the Elixhauser score, were more likely to experience any complication. While this scoring system does estimate disease burden, it has been shown to predict in-patient mortality, which we did not analyze in the current study. With the advent of robotic surgery and urologists' increasing familiarity with performing robotic procedures, more centers are now offering robotic RC. However, debate is ongoing about which approach - open vs. robotic - is superior (Bochner et al., 2015) (Leow et al., 2014). More studies (Smith et al., 2015) are needed to determine which approach results in better patient outcomes.

We did not find any association between health literacy and unplanned healthcare utilization within 90 days, including readmission rate or ED visits. This could be multifactorial, relating to patient knowledge of when he or she should seek medical care as well as patient access to the hospital. Our hospital is a large, tertiary care referral center serving a broad catchment area, with patients sometimes travelling several hundred miles for care. We only collected post-surgical ED visits and readmissions from our own institution and thus are most likely underestimating the true rate of readmission and ED visits, which may have reduced our ability to predict these outcomes. Another explanation may be that some patients require an increased length of stay (rather than readmission), or had additional clinic follow up and thus used the healthcare system in other ways.

A limitation of this analysis is that it is a retrospective review of a prospectively managed database. Although we did adjust our analyses for several factors, we did not account for other factors that have been linked to outcomes following RC including a patient's performance status (using either Karnofsky or World Health Organization scales) or frailty status (Mayr et al., 2012; Revenig et al., 2013). We did not consistently have these data for all patients available and thus included proxy measures, such as comorbidity, BMI, and 
albumin levels. Also, due to the size of our cohort, we were restricted in the number of covariates that could be included. The strengths of this study, however, outweigh our limitations. To our knowledge, this is the first study evaluating the impact of health literacy status on post-operative outcomes following a complex surgical procedure in a generally morbid patient population. We had a large sample size and controlled for a number of clinical and demographic variables that have been shown to be associated with complications previously. Our sample included patients from a large referral center, making the results generalizable to similar institutions where this type of surgery is routinely performed. We also used validated and commonly-used measures like the BHLS, Elixhauser, and Clavien-Dindo classification for our analysis.

\section{Conclusions}

In a retrospective study of a population of patients with $\mathrm{MIBC}$ who underwent $\mathrm{RC}$, lower health literacy was associated with increased odds of having a minor complication. Health literacy status should be considered when caring for these patients and those with lower health literacy identified in advance for additional perioperative instruction in an effort to decrease postoperative morbidity.

\section{Acknowledgments}

We would like to thank John Wanderer for his assistance with this study.

\section{References}

Amin MB, McKenney JK, Paner GP, Hansel DE, Grignon DJ, Montironi R. International Consultation on Urologic Disease-European Association of Urology Consultation on Bladder, C. ICUD-EAU International Consultation on Bladder Cancer 2012: Pathology. European urology. 2013; 63(1):1635. [PubMed: 23083804]

Bochner BH, Dalbagni G, Sjoberg DD, Silberstein J, Keren Paz GE, Donat SM, Laudone VP. Comparing Open Radical Cystectomy and Robot-assisted Laparoscopic Radical Cystectomy: A Randomized Clinical Trial. European urology. 2015; 67(6):1042-1050. [PubMed: 25496767]

Cavanaugh KL, Wingard RL, Hakim RM, Eden S, Shintani A, Wallston KA, Ikizler TA. Low health literacy associates with increased mortality in ESRD. Journal of the American Society of Nephrology : JASN. 2010; 21(11):1979-1985. [PubMed: 20671215]

Chew LD, Bradley KA, Boyko EJ. Brief questions to identify patients with inadequate health literacy. Family medicine. 2004; 36(8):588-594. [PubMed: 15343421]

Chew LD, Griffin JM, Partin MR, Noorbaloochi S, Grill JP, Snyder A, Vanryn M. Validation of screening questions for limited health literacy in a large VA outpatient population. Journal of general internal medicine. 2008; 23(5):561-566. [PubMed: 18335281]

Daneshmand S, Ahmadi H, Schuckman AK, Mitra AP, Cai J, Miranda G, Djaladat H. Enhanced recovery protocol after radical cystectomy for bladder cancer. J Urol. 2014; 192(1):50-55. [PubMed: 24518775]

Donat SM, Siegrist T, Cronin A, Savage C, Milowsky MI, Herr HW. Radical cystectomy in octogenarians--does morbidity outweigh the potential survival benefits? J Urol. 2010; 183(6):21712177. [PubMed: 20399461]

Harris PA, Taylor R, Thielke R, Payne J, Gonzalez N, Conde JG. Research electronic data capture (REDCap)--a metadata-driven methodology and workflow process for providing translational research informatics support. J Biomed Inform. 2009; 42(2):377-381. [PubMed: 18929686]

Kelly PA, Haidet P. Physician overestimation of patient literacy: a potential source of health care disparities. Patient education and counseling. 2007; 66(1):119-122. [PubMed: 17140758] 
Lee CT, Chang SS, Kamat AM, Amiel G, Beard TL, Fergany A, Koch M. Alvimopan accelerates gastrointestinal recovery after radical cystectomy: a multicenter randomized placebo-controlled trial. European urology. 2014; 66(2):265-272. [PubMed: 24630419]

Leow JJ, Reese SW, Jiang W, Lipsitz SR, Bellmunt J, Trinh QD, Chang SL. Propensity-matched comparison of morbidity and costs of open and robot-assisted radical cystectomies: a contemporary population-based analysis in the United States. European urology. 2014; 66(3):569_ 576. [PubMed: 24491306]

Lowrance WT, Rumohr JA, Chang SS, Clark PE, Smith JA Jr, Cookson MS. Contemporary open radical cystectomy: analysis of perioperative outcomes. J Urol. 2008; 179(4):1313-1318. discussion 1318. [PubMed: 18289578]

Mayr R, May M, Martini T, Lodde M, Comploj E, Pycha A, Fritsche HM. Comorbidity and performance indices as predictors of cancer-independent mortality but not of cancer-specific mortality after radical cystectomy for urothelial carcinoma of the bladder. European urology. 2012; 62(4):662-670. [PubMed: 22534059]

Morgan T, Keegan K, Barocas D, Ruhotina N, Phillips S, Chang S, Penson D, Clark P, Smith J, Cookson M. Predicting the probability of 90-day survival of elderly patients with bladder cancer treated with radical cystectom. Journal of Urology. 2011; 186(3):829-834. [PubMed: 21788035]

Nielsen-Bohlman, L. Institute of Medicine (U.S.). Committee on Health Literacy. Health literacy : a prescription to end confusion. Washington, D.C.: The National Academies Press; 2004.

Peterson PN, Shetterly SM, Clarke CL, Bekelman DB, Chan PS, Allen LA, Masoudi FA. Health literacy and outcomes among patients with heart failure. JAMA : the journal of the American Medical Association. 2011; 305(16):1695-1701. [PubMed: 21521851]

Revenig LM, Canter DJ, Taylor MD, Tai C, Sweeney JF, Sarmiento JM, Ogan K. Too frail for surgery? Initial results of a large multidisciplinary prospective study examining preoperative variables predictive of poor surgical outcomes. J Am Coll Surg. 2013; 217(4):665-670. e661. [PubMed: 24054409]

Safeer RS, Keenan J. Health literacy: the gap between physicians and patients. Am Fam Physician. 2005; 72(3):463-468. [PubMed: 16100861]

Schiffmann J, Gandaglia G, Larcher A, Sun M, Tian Z, Shariat SF, Karakiewicz PI. Contemporary 90day mortality rates after radical cystectomy in the elderly. Eur J Surg Oncol. 2014; 40(12):17381745. [PubMed: 25454826]

Shabsigh A, Korets R, Vora KC, Brooks CM, Cronin AM, Savage C, Donat SM. Defining early morbidity of radical cystectomy for patients with bladder cancer using a standardized reporting methodology. European urology. 2009; 55(1):164-174. [PubMed: 18675501]

Siegel RL, Miller KD, Jemal A. Cancer statistics, 2015. CA: a cancer journal for clinicians. 2015; 65(1):5-29. [PubMed: 25559415]

Smith ND, Castle EP, Gonzalgo ML, Svatek RS, Weizer AZ, Montgomery JS, Pruthi RS, Woods ME, Tollefson MK, Konety BR, Shabsigh A, Krupski T, Barocas DA, Dash A, Quek ML, Kibel AS, Parekh DJ. The RAZOR (randomized open vs robotic cystectomy) trial: study design and trial update. British Journal of Urology International. 2015; 115(2):198-205.

Stein JP, Lieskovsky G, Cote R, Groshen S, Feng AC, Boyd S, Skinner DG. Radical cystectomy in the treatment of invasive bladder cancer: long-term results in 1,054 patients. Journal of clinical oncology : official journal of the American Society of Clinical Oncology. 2001; 19(3):666-675. [PubMed: 11157016]

Stimson CJ, Chang SS, Barocas DA, Humphrey JE, Patel SG, Clark PE, Cookson MS. Early and late perioperative outcomes following radical cystectomy: 90-day readmissions, morbidity and mortality in a contemporary series. J Urol. 2010; 184(4):1296-1300. [PubMed: 20723939]

van Walraven C, Austin PC, Jennings A, Quan H, Forster AJ. A modification of the Elixhauser comorbidity measures into a point system for hospital death using administrative data. Medical care. 2009; 47(6):626-633. [PubMed: 19433995]

Willens DE, Kripalani S, Schildcrout JS, Cawthon C, Wallston K, Mion LC, Roumie CL. Association of brief health literacy screening and blood pressure in primary care. Journal of health communication. 2013; 18(Suppl 1):129-142. [PubMed: 24093351] 
Zaid HB, Kaffenberger SD, Chang SS. Improvements in safety and recovery following cystectomy: reassessing the role of pre-operative bowel preparation and interventions to speed return of postoperative bowel function. Curr Urol Rep. 2013; 14(2):78-83. [PubMed: 23397271] 


\section{LEARNING READINESS}

First say: "Many patients have trouble understanding the medical information they receire at the hospital or doctor's office."

How confident are you filling out medical forms by yourself?

$\square$ Extremely $\square$ Quite a bit $\square$ Somewhat

A little bit

Not at all

How often do you have someone help you read hospital materials? $\square$ All of the time $\square$ Most of the time $\square$ Some of the time A little of the time $\square$ None of the time

How often do you have problems learning about your medical condition because of difficulty understanding written information?

$\square$ All of the time $\square$ Most of the time $\square$ Some of the time $\square$ A little of the time $\square$ None of the time

Figure 1.

Brief Health Literacy Screen as seen in our EHR 
Age, vars

Fernale

Non-white race

Health Literacy score

Education, years

Tumor stage: T2 (ST1mref)

Tumor stage: T3 (STLref)

Prepo Chemo

ASA Class (class 2-ren!)

Eltrhauser soare

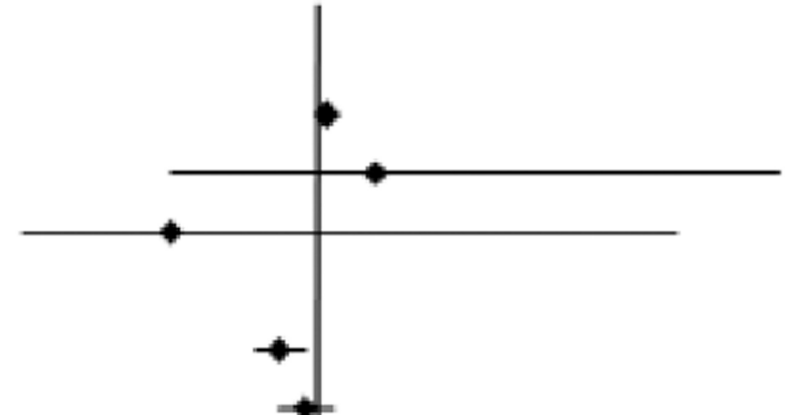

OR [95\% Confidence interval]

$1.03(1.00,1.07)$

$1.17(0.59,2.31)$

$0.59(0.17,2.02)$

$0.90(0.83,0.97)^{*}$

$0.97[0,50,1,05\}$

$1.33(0.66,2.70)$

$1.16(0,60,2,26)$

$1.12(0.62,2.01)$

1.08 (0.59, 1.58)

$1.03(0,99,1,05)$

Odds ratio [OR]

Lesi odds of hwing a eomplieation

Graster odds of havilng a camplication

Figure 2.

Logistic regression model results predicting minor complication after surgery (controlling for all covariates).

*p-value $<0.05$ 
Table 1

Demographics and clinical characteristics according to BHLS score

\begin{tabular}{|c|c|c|c|c|}
\hline CHARACTERISTIC & $\begin{array}{c}\text { LOW HL } \\
\text { (BHLS 3-13) } \\
\text { N=188 }\end{array}$ & $\begin{array}{c}\text { HIGH HL } \\
\text { (BHLS 14-15) } \\
\text { N=180 }\end{array}$ & $\begin{array}{l}\text { TOTAL } \\
\mathbf{N = 3 6 8}\end{array}$ & P-value \\
\hline Age, Mean \pm SD & $67.3 \pm 9.6$ & $67.1 \pm 9.2$ & $67.2 \pm 9.4$ & 0.946 \\
\hline Race, white, $\mathrm{n}(\%)$ & $175(93.6)$ & $175(98.3)$ & $350(95.9)$ & $0.032^{*}$ \\
\hline Gender, male, $\mathrm{n}(\%)$ & $151(80.3)$ & $156(86.7)$ & $307(83.4)$ & 0.102 \\
\hline Education, years, Mean \pm SD & $12.6 \pm 3.4$ & $14.0 \pm 2.9$ & $13.3 \pm 3.2$ & $<0.001^{*}$ \\
\hline Married & $127(69.4)$ & $150(84.3)$ & $277(76.7)$ & $0.001^{*}$ \\
\hline \multicolumn{5}{|l|}{ Insurance } \\
\hline Self-pay & $7(3.8)$ & $6(3.4)$ & $13(3.6)$ & 0.558 \\
\hline Medicaid/Medicare/Medicare HMO & $121(65.8)$ & $109(60.9)$ & $230(63.4)$ & \\
\hline Private & $56(30.4)$ & $64(35.8)$ & $120(33.1)$ & \\
\hline Pathologic Stage, n(\%) & & & & $0.022^{*}$ \\
\hline pT0 & $9(5.0)$ & $7(4.0)$ & $16(4.5)$ & \\
\hline pTis, pTa, pT1 & $53(29.3)$ & $68(38.4)$ & $121(33.8)$ & \\
\hline pT2 & $43(23.8)$ & $38(21.5)$ & $81(22.6)$ & \\
\hline pT3 & $56(30.9)$ & $59(33.3)$ & $115(32.1)$ & \\
\hline pT4 & $20(11.0)$ & $5(2.8)$ & $25(7.0)$ & \\
\hline Albumin, Mean \pm SD & $4.0 \pm 0.3$ & $4.1 \pm 0.4$ & $4.1 \pm 0.3$ & $0.001^{*}$ \\
\hline Creatinine, Mean \pm SD & $1.2 \pm 0.4$ & $1.2 \pm 0.5$ & $1.2 \pm 0.5$ & 0.947 \\
\hline Elixhauser score, Mean \pm SD & $10.1 \pm 7.4$ & $9.9 \pm 8.1$ & $10.0 \pm 7.7$ & 0.495 \\
\hline Prior abdominal surgery, $\mathrm{n}(\%)$ & $123(65.4)$ & $112(63.6)$ & $235(64.6)$ & 0.721 \\
\hline Current smoker & $43(23.0)$ & $28(15.6)$ & $71(19.3)$ & 0.071 \\
\hline Procedure, $\mathrm{n}(\%)$ & & & & 0.792 \\
\hline Open & $139(73.9)$ & $133(75.1)$ & $272(74.5)$ & \\
\hline Robotic & $49(26.1)$ & $44(24.9)$ & $93(25.5)$ & \\
\hline Diversion, $\mathrm{n}(\%)$ & & & & 0.418 \\
\hline Ileal conduit & $154(81.9)$ & $137(76.5)$ & $291(79.3)$ & \\
\hline Neobladder & $29(15.4)$ & $37(20.7)$ & $66(18.0)$ & \\
\hline Other & $5(2.7)$ & $5(2.8)$ & $10(2.7)$ & \\
\hline BMI, Mean \pm SD & $28.4 \pm 5.4$ & $29.0 \pm 5.5$ & $28.7 \pm 5.4$ & 0.430 \\
\hline Neoadjuvant chemotherapy, n (\%) & $57(30.3)$ & $42(23.3)$ & $99(26.9)$ & 0.131 \\
\hline ASA status, n (\%) & & & & 0.286 \\
\hline 2 & $36(19.1)$ & $45(25.2)$ & $81(22.1)$ & \\
\hline 3 & $142(75.5)$ & $128(71.5)$ & $270(73.5)$ & \\
\hline 4 & $10(5.3)$ & $6(3.4)$ & $16(4.4)$ & \\
\hline \multicolumn{5}{|l|}{ BX path stage } \\
\hline Tis & $8(4.3)$ & $8(4.5)$ & $16(4.4)$ & $0.002^{*}$ \\
\hline $\mathrm{Ta}$ & $10(5.4)$ & $23(13.0)$ & $33(9.1)$ & \\
\hline $\mathrm{T} 1$ & $37(20.1)$ & $55(31.1)$ & $92(25.5)$ & \\
\hline
\end{tabular}




\begin{tabular}{lcccc}
\hline CHARACTERISTIC & $\begin{array}{c}\text { LOW HL } \\
(\text { BHLS 3-13) } \\
\text { N=188 }\end{array}$ & $\begin{array}{c}\text { HIGH HL } \\
(\text { BHLS 14-15) } \\
\text { N=180 }\end{array}$ & $\begin{array}{c}\text { TOTAL } \\
\text { N=368 }\end{array}$ & P-value \\
\hline T2 or higher & $129(70.1)$ & $91(51.4)$ & $220(60.9)$ & \\
\hline${ }^{*}$ p-value $<0.05$ & & & \\
${ }^{a}$ Mann-Whitney U test conducted on all continuous variables & \\
${ }^{b}$ Chi-square or Fisher's exact test conducted on all categorical variables &
\end{tabular}

${ }^{c}$ Missing= race (3), BX path stage (7), tStage (10), albumin (73), ASA (1), smoking status (1), marital status (7), insurance (5), education (28), prior abdominal surgery (4), procedure (3), diversion (1), creatinine (10), BMI (10), Elixhauser (1)

[Pathologic stage refers to TNM (primary Tumor, regional lymph Nodes, and distant Metastasis) staging categories at the time of RC while Bx (biopsy) pathologic stage refers to staging at the time of pre-cystectomy transurethral resection - T0 no residual disease, Ta noninvasive papillary, Tis carcinoma in situ, T1 invasion of subepithelial tissue, T2 invasion of muscularis propria, T3 invasion of perivesical tissue, T4 invasion of prostate, seminal vesicles, uterus, vagina, pelvic wall, abdominal wall ASA = American Society of Anesthesiologists Classification: ASA I normal healthy patient, ASA II a patient with mild systemic disease, ASA III a patient with severe systemic disease, ASA IV a patient with severe systemic disease that is a constant threat to life, ASA V a moribund patient who is not expected to survive without the operation.] 


\section{Table 2}

Health outcomes according to literacy status (Bivariate analysis)

\begin{tabular}{lcccc} 
OUTCOME & $\begin{array}{c}\text { LOW HL } \\
(\mathbf{B H L S ~ 3 - 1 3 )} \\
\mathbf{N = 1 8 8}\end{array}$ & $\begin{array}{c}\text { HIGH HL } \\
(\mathbf{B H L S ~ 1 4 - 1 5 )})\end{array}$ & $\begin{array}{c}\text { TOTAL } \\
\text { N=180 }\end{array}$ & P-Value \\
\hline Any complication 30 day, n (\%) & $88(46.8)$ & $69(38.3)$ & $157(42.7)$ & 0.100 \\
Major complication 30 day, n (\%) & $14(7.4)$ & $17(9.4)$ & $31(8.4)$ & 0.490 \\
Minor complication 30 day, n (\%) & $74(39.4)$ & $52(28.9)$ & $126(34.2)$ & $0.034^{*}$ \\
Readmission 90 day, n (\%) & $40(21.3)$ & $41(22.8)$ & $81(22.0)$ & 0.728 \\
Days to first readmission, Median (IQR) & $11.5(5.0-23.3)$ & $13.0(5.5-24.0)$ & $13.0(5.0-23.5)$ & 0.574 \\
ED visit 90 day, n(\%) & $33(17.6)$ & $34(18.9)$ & $67(18.2)$ & 0.740 \\
Days to first ED visit, Median (IQR) & $9.0(4.0-24.5)$ & $12.0(5.0-23.5)$ & $10.0(5.0-24.0)$ & 0.890 \\
\hline
\end{tabular}

p-value $<0.05$ 